International Journal of Pure and Applied Mathematics

Volume 113 No. 1 2017, 43-47

ISSN: 1311-8080 (printed version); ISSN: 1314-3395 (on-line version)

url: http://www.ijpam.eu

doi: 10.12732/ijpam.v113i1.5

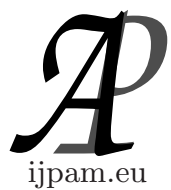

\title{
NUMERICAL ALGORITHM FOR SOLVING OPTIMAL CONTROL PROBLEMS BY THE METHOD OF LOCAL VARIATIONS
}

\author{
Igor Grigoryev $^{1}$, Svetlana Mustafina ${ }^{2}$ \\ ${ }^{1,2}$ Bashkir State University \\ 32, Validy Str., 450076, Ufa, RUSSIA
}

\begin{abstract}
In this article we gave a description of an algorithm of the method of local variations for numerical solution of problems of optimal control. We have developed a program based on the method of local variations to solve the optimal control problems with free right end. Finally, a numerical example is presented to demonstrate effectiveness, simplicity and accuracy of the proposed method.
\end{abstract}

AMS Subject Classification: 49M30, 65K05, 65K10

Key Words: method of local variations, optimal control, phase variables, numerical solution

\section{Introduction}

Control theory is application-oriented mathematics that deals with the basic principles underlying the analysis and design of (control) systems. Systems can be engineering systems (air conditioner, aircraft, CD player etcetera), economic systems, biological systems and so on. To control means that one has to influence the behaviour of the system in a desirable way: for example, in the case of an air conditioner, the aim is to control the temperature of a room and maintain it at a desired level, while in the case of an aircraft, we wish to

$\begin{array}{lr}\text { Received: } & \text { October 9, } 2016 \\ \text { Revised: } & \text { December 12, } 2016 \\ \text { Published: } & \text { February 28, } 2017\end{array}$

(c) 2017 Academic Publications, Ltd. url: www.acadpubl.eu 
control its altitude at each point of time so that it follows a desired trajectory. As a result, more and more people will benefit greatly by learning to solve the optimal control problems numerically.

\section{Problem Statement}

Consider the following optimal control problem:

$$
\text { minimize } I(u)=\int_{t_{0}}^{T} f^{0}(t, x(t), u(t)) d t,
$$

subject to

$$
\begin{gathered}
\frac{d x_{i}}{d t}=f_{i}(t, x(t), u(t)), \quad t \in\left[t_{0}, T\right], x(0)=x_{0}, \\
\phi(u) \leq 0,
\end{gathered}
$$

where $u(t) \in R$ is the function characterizing the operating influence, $x(t) \in R^{n}$ is function describing a condition of process and $t$ is time.

\section{Method of Local Variations}

The algorithm consists of 9 steps:

1. Guess an initial approximation of control $U_{0}$.

2. Break interval $\left[t_{0}, T\right]$ to $n$ parts, constituting a uniform system of units.

3. Select starting node $t_{0}$, which will be a variation of controls.

4. Compute $U\left(t_{0}\right) \pm \delta U$.

5. Compute $x(t)$ and $u(t)$, solving (2).

6. Calculate $I(u)$ according to (1).

7. Go to $t_{1}$ and go to step 4 for all remaining points $t_{i}$.

8. Determine the minimum value of the criterion calculated for all points $t_{i}$ and define a new control $U_{1}$ corresponds to the lowest value criterion.

9. Set $\delta U=\frac{\delta U}{2}$. Then, with the control $U_{1}$, go to step 3 until will not find variation in which the performance criterion will not be improved. 


\section{Discussion}

The software for the numerical calculations presented below in this article was developed in Borland Delphi environment. In the following example we compute the absolute errors in the following specified norms:

$$
\begin{gathered}
\varepsilon_{x_{1}}=\sqrt{\sum_{i}\left(x_{1_{i}}-x_{1}^{*}\left(t_{i}\right)\right)^{2}}, \quad \varepsilon_{x_{2}}=\sqrt{\sum_{i}\left(x_{2_{i}}-x_{2}^{*}\left(t_{i}\right)\right)^{2}}, \\
\varepsilon_{u}=\sqrt{\sum_{i}\left(u_{i}-u^{*}\left(t_{i}\right)\right)^{2}} .
\end{gathered}
$$

Example. Consider the following optimal control system:

$$
\begin{gathered}
\left\{\begin{array}{c}
\dot{x}_{1}(t)=x_{2}(t), \\
\dot{x}_{2}(t)=u(t) ;
\end{array}\right. \\
x_{1}(0)=-1, \quad x_{2}(0)=0, \\
0 \leq t \leq 2.5, \\
|u| \leq 1, \\
x_{2} \leq 0.5 .
\end{gathered}
$$

The performance measure is:

$$
I\left(x_{1}, x_{2}\right)=x_{1}^{2}(2.5)+x_{2}^{2}(2.5) \rightarrow \min .
$$

The optimal control problem is to find a control law $u^{*}(\cdot)$ which minimizes cost functional (5).

The exact solution is:

$$
u^{*}(t)=\left\{\begin{array}{l}
1, t \leq 0.5 \\
0,0.5<t<2 \\
-1,2 \leq t \leq 2.5
\end{array}\right.
$$

Figure 1 and Figure 2 show the comparison between numerical solution and approximate solution for $u_{0}=0.1$. In Table 1 , we present the simulation results for different initial guess and accuracy of this problem. 


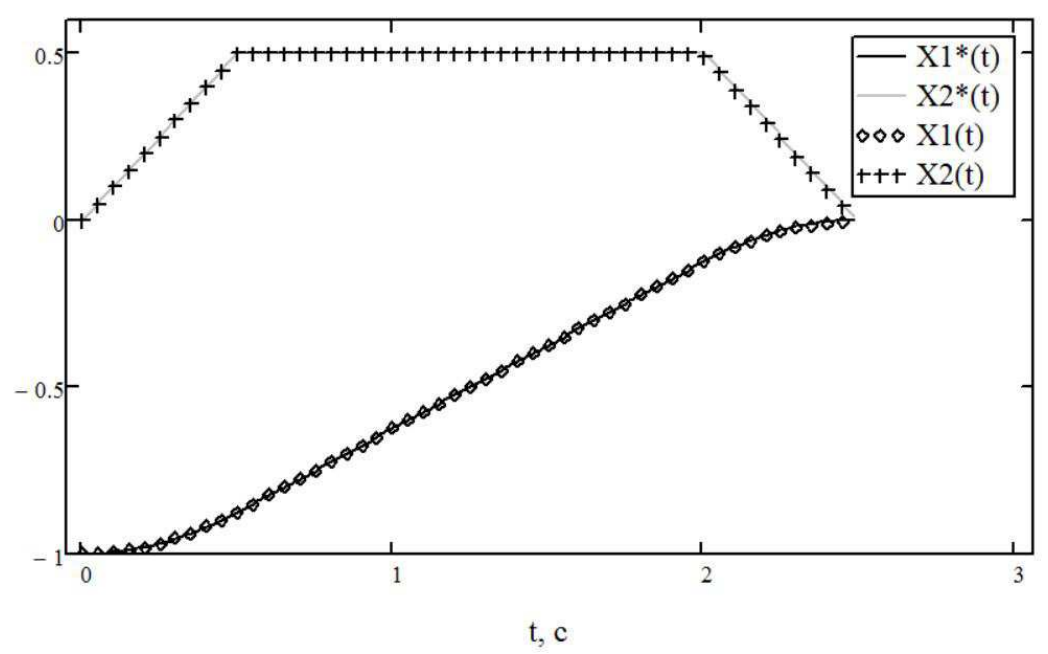

Figure 1: The suboptimal states

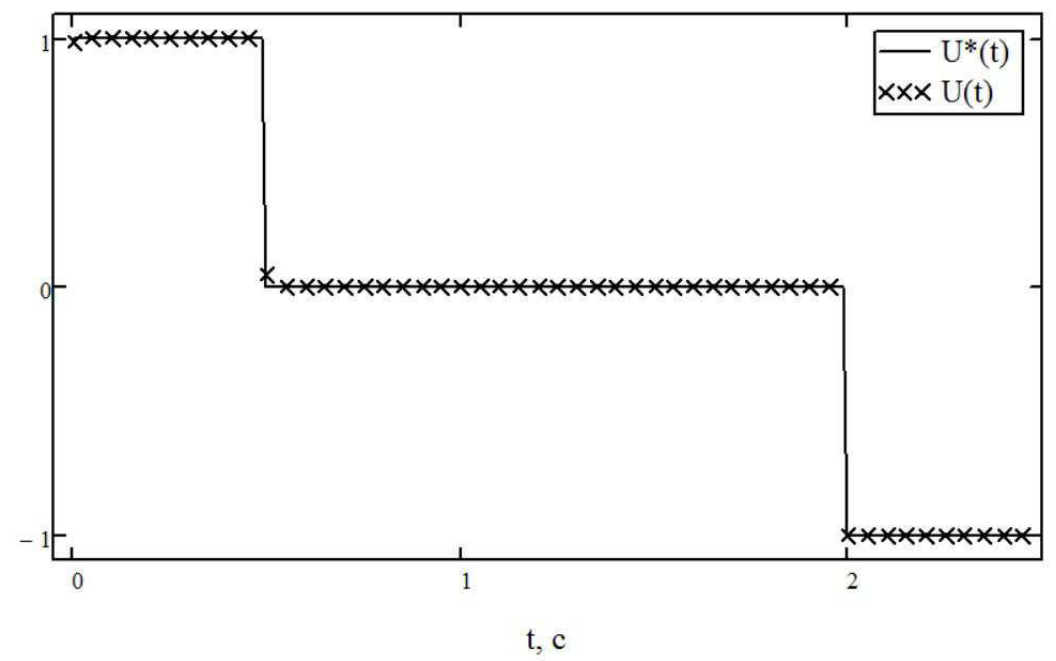

Figure 2: The suboptimal control

\section{Conclusion}

For many optimal control problems, the method of variations is the best option we have. The advantage of this algorithm is anabsence of requirements to the choice of initial approximation of the parameter of controlling and phase 


\begin{tabular}{|c|c|c|c|c|c|c|}
\hline & $u_{0}$ & Accuracy & Error $\varepsilon_{u}$ & Error $\varepsilon_{x_{1}}$ & Error $\varepsilon_{x_{2}}$ & $I_{\min }$ \\
\hline 1 & 0 & 0,1 & 5,46 & 2,97 & 2,58 & 0,15 \\
\hline 2 & 0 & 0,01 & 1,79 & 0,09 & 0,102 & 0,0001 \\
\hline 3 & 0 & 0,001 & 1,807 & 0,088 & 0,102 & 0,0001 \\
\hline 4 & $-0,6$ & 0,001 & 1,695 & 0,096 & 0,102 & 0,0001 \\
\hline 5 & $-0,9$ & 0,0001 & 1,5092 & 0,0885 & 0,1026 & 0,0001 \\
\hline 6 & 0,1 & 0,00001 & 1,50543 & 0,08875 & 0,10224 & 0,00014 \\
\hline
\end{tabular}

Table 1: Simulation results for different initial guess and accuracy

variables. The algorithm is characterized by a good convergence and can be used to solve a large number of applications in various fields of national economy.

\section{References}

[1] Igor Grigoryev, Svetlana Mustafina, Global optimization of functions of several variables using parallel technologies, International Journal of Pure and Applied Mathematics, 106, No. 1 (2016), 301-306, doi: 10.12732/ijpam.v106i1.24.

[2] Gulnaz Shangareeva, Igor Grigoryev, Svetlana Mustafina, Comparative analysis of numerical solution of optimal control problems, International Journal of Pure and Applied Mathematics, 110, No. 4 (2016), 645-649, doi: 10.12732/ijpam.v110i4.6.

[3] Igor Grigoryev, Eldar Miftakhov, Svetlana Mustafina, Mathematical modelling of the copolymerization of styrene with maleic anhydride in a homogeneous environment, International Journal of Chemical Sciences, 14, No. 1 (2016), 381-386. 
